\title{
Risk of adverse events associated with upper and lower endoscopic ultrasound: a population-based cohort study
}

\section{다(1) $(\odot$}

\section{Authors}

Roshan Razik*,, Paul D. James*,2, Rishad Khan², Courtney Maxwell ${ }^{3}$, Yibing Ruan ${ }^{4}$, Nauzer Forbes ${ }^{3,5}$, Anita Williams $^{6}$, Divine Tanyingoh ${ }^{3}$, Darren R. Brenner ${ }^{4,5}$, Gilaad G. Kaplan ${ }^{3,5}$, Robert J. Hilsden ${ }^{3,5}$, Steven J. Heitman ${ }^{3,5}$

Institutions

1 Cleveland Clinic Akron General, Akron, Ohio, United States

2 Department of Medicine, University Health Network, University of Toronto, Faculty of Medicine, Toronto, Ontario, Canada

3 Department of Medicine, University of Calgary, Cumming School of Medicine, Calgary, Alberta, Canada

4 Department of Cancer Epidemiology and Prevention Research, Cancer Care Alberta, Alberta Health Services, Calgary, Alberta, Canada

5 Department of Community Health Sciences, University of Calgary, Cumming School of Medicine, Calgary, Alberta, Canada

6 Analytics, Data Integration, Measurement and Reporting, Alberta Health Services, Calgary, Alberta, Canada

submitted 17.12 .2020

accepted after revision 5.5 .2021

Bibliography

Endosc Int Open 2021; 09: E1427-E1434

DOI 10.1055/a-1512-9341

ISSN 2364-3722

(c) 2021. The Author(s).

This is an open access article published by Thieme under the terms of the Creative Commons Attribution-NonDerivative-NonCommercial License, permitting copying and reproduction so long as the original work is given appropriate credit. Contents may not be used for commercial purposes, or adapted, remixed, transformed or built upon. (https://creativecommons.org/licenses/by-nc-nd/4.0/)

Georg Thieme Verlag KG, Rüdigerstraße 14,

70469 Stuttgart, Germany

Corresponding author

Steven J. Heitman, MD, Department of Medicine, University of Calgary, Cumming School of Medicine, TRW Building, 3280 Hospital Drive NW, Calgary, AB T2N 4Z6, Canada

Fax: +1-403-592-5090

steven.heitman@ucalgary.ca

\section{ABSTRACT}

Background and study aim Endoscopic ultrasound (EUS) enables diagnostic evaluation and therapeutic interventions but is associated with adverse events. We conducted a population-based cohort study to determine the risk of adverse events for upper and lower EUS with and without fine-needle aspiration (FNA).

Patients and methods All adults who underwent EUS and resided in Calgary in 2007-2013 were included. Endoscopy and provincial databases were used to identify EUS procedures, unplanned emergency department visits, and hospital admissions within 30 days of the procedures, which were then characterized through formal chart review. Adverse events were defined a priori and classified as definitely, possibly, or not related to EUS. The primary outcome was 30day risk of adverse events classified as definitely or possibly related to EUS. Univariable and multivariable analyses were conducted with risk factors known to be associated with EUS adverse events.

Results 2895 patients underwent 3552 EUS procedures: 3034 (85\%) upper EUS, of which 710 (23\%) included FNA, and $518(15 \%)$ lower EUS, of which 23 (4\%) involved FNA. Overall, 69 procedures ( $2 \%$ involved an adverse event that was either definitely or possibly related to EUS, with 33 (1\%) requiring hospitalization. None of the adverse events required intensive care or resulted in death. On multivariable analysis, only FNA was associated with increased risk of adverse events (odds ratio 6.43, $95 \%$ confidence interval 3.92-10.55; $P<0.001)$.

Conclusion Upper and lower EUS were generally safe but FNA substantially increased the risk of adverse events. EUS-related complications requiring hospitalization were rare.

\footnotetext{
${ }^{*}$ These authors contributed equally to this work.
} 


\section{Introduction}

Endoscopic ultrasound (EUS) enables minimally invasive diagnostic evaluation and therapeutic interventions for patients with gastrointestinal (Gl) and pancreaticobiliary disorders. However, EUS exposes patients to adverse events such as bleeding, infection, pancreatitis, perforation, and death [1-6]. Accurate data regarding the risks of adverse events and the modifiable factors associated with these events can enable patients and their caregivers to make informed decisions regarding their care and minimize procedure-related harm following EUS [7].

Although numerous original studies and several meta-analyses have reported on the risks of EUS-associated adverse events, estimates to date have important limitations $[1,8]$. Most original studies only report data on intraprocedural and early post-procedural adverse events without follow-up to 30 days to capture delayed events. In a 2011 review on this topic, Wang et al. [1]. reported that only two of the 41 studies in their meta-analysis followed patients to assess for delayed adverse events $[9,10]$. In addition, most studies have been designed with diagnostic yield as a primary outcome and thus may not provide precise estimates of adverse event risks.

Data on lower EUS for rectal and pelvic lesions are scant. Among the few studies that have reported on lower EUS adverse events, risks have been as high as $15 \%-21 \%[11,12]$. Many participants, however, underwent other procedures concurrently with their lower EUS with fine-needle aspiration (FNA), including colonoscopy and polypectomy [11]. Moreover, few studies in the upper and lower EUS literature report on adverse events related to EUS alone, with the majority reporting on EUS with FNA.

The objectives of this study were to evaluate the risk of adverse events following EUS and to assess risk factors for EUSassociated events. In addition, we differentiated EUS-associated adverse events following upper vs. lower EUS and following EUS with and without FNA.

\section{Patients and methods}

\section{Study design and setting}

This population-based retrospective cohort study examined patients who underwent EUS while residing in the Calgary Zone (CZ) from 2007 to 2013. The CZ provides publicly funded health care services to approximately 1.4 million people in the Canadian province of Alberta. All EUS procedures were performed at the Foothills Medical Centre, the largest tertiary care facility in Alberta, by one of six consultant endoscopists who had formal training in EUS or by a therapeutic endoscopy trainee under direct supervision from the consultant. The study received institutional review board approval by the University of Calgary's Conjoint Health Research Ethics Board (REB142312).

\section{Study cohort}

All adult CZ patients who underwent one or more outpatient EUS procedure were eligible for inclusion. We restricted the co- hort to $C Z$ patients to eliminate the possibility of not being able to conduct chart reviews among non-CZ patients who traveled to Calgary for their procedure, but later presented to an outside hospital after returning home. Patients were initially identified through the electronic reporting program endoPRO (Pentax Medical, Montvale, New Jersey, USA) used to document all endoscopic procedures in Calgary. Patients with no procedure reports, and those under the age of 18 years were excluded. Additionally, we excluded pancreatic cyst ablation with ethanol and cyst gastrostomy procedures due to low sample sizes. We further excluded patients who underwent EUS-guided celiac plexus block or neurolysis (CPB/CPN), as the indication for these procedures was abdominal pain and the majority of presentations to hospital after the procedure were for ongoing abdominal pain; we could not have determined whether the EUS procedure contributed to their pain or was simply ineffective. Patients who underwent EUS were administered conscious sedation by nursing staff under the direction of the attending physician.

\section{Data sources and variables}

Study investigators (R.R., N.F.) abstracted demographic (age, sex), clinical (procedure indication), and procedural data (sedation used, presence of a trainee, EUS approach [upper vs. lower], type of echoendoscope used [radial vs. linear], needle sampling method and number of passes when applicable, and concurrence of other endoscopic procedures [endoscopic retrograde cholangiopancreatography (ERCP)] or colonoscopy) through review of each of the procedure reports. Esophagogastroduodenoscopy and flexible sigmoidoscopy were not considered additional procedures as these are routinely performed along with upper and lower EUS, respectively.

Using each patient's regional health record number, the procedural dataset was then linked to provincial emergency department and hospital discharge databases to identify all visits to the emergency department and/or unplanned inpatient admissions occurring anywhere in the $C Z$ within 30 days of the EUS procedures. The electronic health record for each of these encounters was individually reviewed by a trained research assistant (C.M.). Data abstracted included the presenting complaint, treatment disposition (discharge home, admission), final diagnosis, length of hospital stay, need for interventions (endoscopic procedure, surgery, antibiotics, admission to intensive care, blood transfusion), and vital status.

\section{Classification of adverse events}

We defined a potential adverse event a priori as any emergency department visit or unplanned hospitalization that involved a main diagnosis that has been previously reported as EUS related, including abdominal pain, fever, pancreatitis, bleeding, infection, perforation, cardiopulmonary event, or death. Planned hospitalizations were excluded from the analysis.

Using a previously reported approach to evaluating adverse events related to endoscopic procedures [13-15], three investigators (R.R., P.D.J., and S.J.H.) independently determined the causal relationship of each clinical encounter to the index EUS procedure by applying predefined criteria: 1 ) no other exposure 
was more likely than the EUS procedure to be related to the event, 2) the event was a new clinical presentation for the patient (i.e. not due to a pre-existing condition prior to the EUS exposure), and 3) the event was a previously reported adverse event of EUS. Events that met all three criteria were classified as "definitely related"; those meeting none of these criteria were classified as "not related." Finally, events that met at least one but not all criteria were classified as "possibly related." Disagreements were resolved by consensus.

In cases where patients had more than one definitely or possibly related adverse event following an EUS procedure, investigators identified and prioritized the most clinically significant and closely timed encounter relative to the EUS. One adverse event was permitted per procedure.

\section{Data analysis}

The primary outcome was the 30-day risk of adverse events categorized as definitely or possibly related to the EUS procedure. We also examined associations among patient, procedure, and endoscopist characteristics and adverse events through univariable and multivariable analyses.

Categorical variables were reported as proportions and comparisons were made using Fisher's exact tests. We conducted univariable analyses on a priori selected risk factors previously shown to be associated with EUS adverse events, including patient age ( $\geq 65$ vs. $<65$ years) [16-18], sex [19], presence of a trainee [13], and the use of FNA [20]. To account for the possibility of differential risks of adverse events between patients who only had one EUS procedure and those who underwent multiple procedures during the study period, we included the performance of multiple EUS procedures, compared with a single procedure, as a binary variable. Finally, given that the completion of additional endoscopic procedures concurrently with EUS could be associated with higher adverse event risk [11], we also included "additional procedures" (same-day ERCP or colonoscopy) as a potential risk factor. These risk factors were used for univariable and multivariable logistic regression, with estimates provided using odds ratios (ORs) with $95 \%$ confidence intervals (Cls). Given that adverse events after EUS are considered a rare event, we used Firth's logistic regression to reduce the bias in maximum likelihood estimates. All statistical analyses were completed using STATA (StataCorp. 2017. Stata Statistical Software: Release 15. College Station, Texas, USA).

\section{Results}

Among the 2913 patients assessed for eligibility, those with missing procedure reports $(n=1)$ and those aged under 18 years $(n=3)$ were excluded. We also excluded one patient who underwent one pancreatic cyst ablation with ethanol, three who underwent one cyst gastrostomy procedure each, and 10 who underwent 37 EUS-guided celiac plexus interventional procedures ( $>$ Fig. 1 ). Five patients who underwent EUS-CPN or CPB presented to the emergency department within 30 days of their procedure. Two of these patients had abdominal pain considered to be related to the EUS-CPN procedure; one of these patients had undergone concurrent EUS-FNA and one

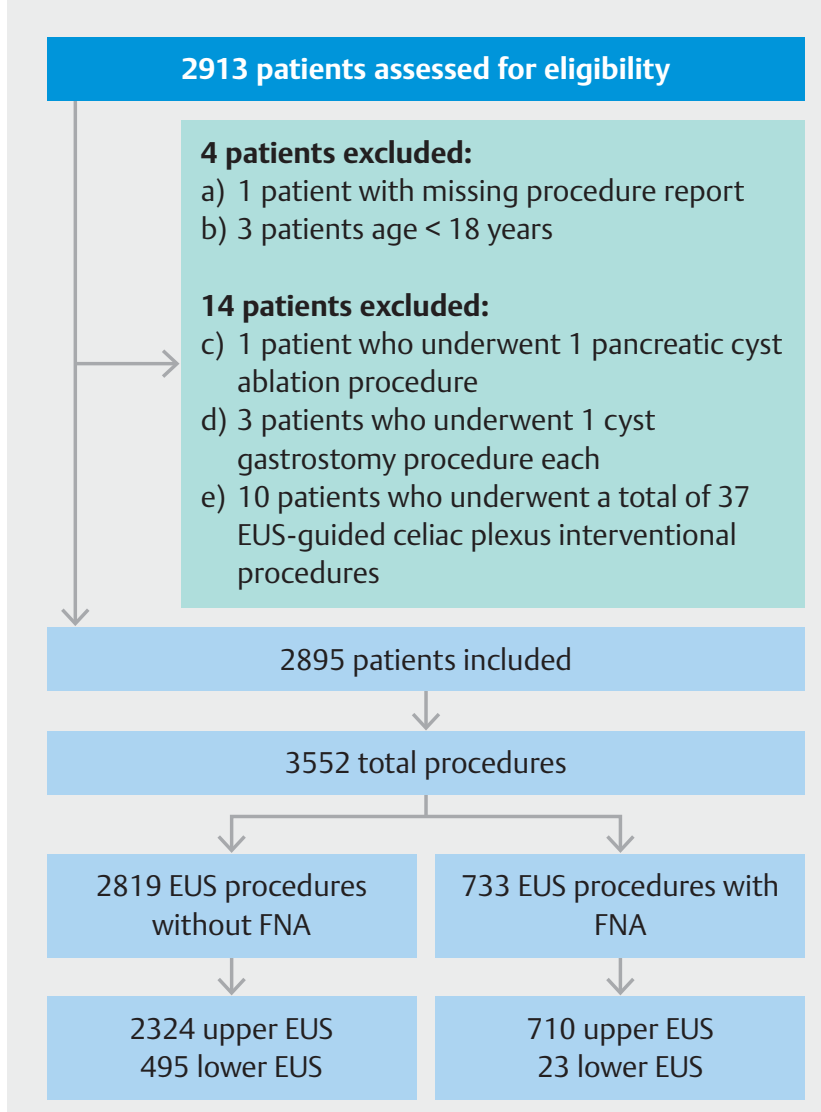

- Fig. 1 Study flow diagram. EUS, endoscopic ultrasound; FNA, fine-needle aspiration.

had not. None of the patients had perforation, infection, or bleeding. Owing to the uncertainty of the three post-procedure presentations with abdominal pain and their relation to the procedure vs. their underlying pancreatic cancer, this group was excluded from the analyses. Thus, the final study cohort comprised 2895 patients who underwent a total of 3552 procedures, including those with $(n=733)$ and without $(n=2819)$ FNA.

The median age of the 2895 patients in the final cohort was 59.7 years and $53 \%$ were male. There were 3034 upper EUS procedures, of which 710 included FNA (23\%), and 518 lower EUS procedures, of which 23 (4\%) involved FNA. The most common indications for EUS were for assessment of hepatopancreaticobiliary lesions (pancreatic cyst, pancreatic mass, bile or pancreatic duct stone, bile duct stricture, and chronic pancreatitis) $(n=1773,50 \%)$, gastrointestinal subepithelial lesions ( $n=$ $1334,38 \%$ ), and other indications ( $n=373,11 \%)$, which included hepatopancreaticobiliary lesions other than those mentioned above and nonluminal soft tissue or cystic lesions. Linear and radial echoendoscopes were used for 960 (27\%) and 2592 (73\%) procedures, respectively.

Conscious sedation was used during 3062 procedures (86\%) and general anesthesia in only 64 procedures ( $2 \%$ ). No sedation was used for the remaining 426 procedures, $93 \%$ of which were lower EUS procedures. A fellow was present for 2211 proce- 
dures (62\%). A complete colonoscopy or ERCP was performed concurrently in $67(2 \%)$ and $33(1 \%)$ procedures, respectively. Among the 733 procedures that involved FNA, a 22- or 25gauge needle was used for 514 procedures (70\%) and a 19gauge needle was used for 75 procedures (10\%). The endoscopist performed $1-3$ passes for 547 procedures (75\%), and $>3$ passes for $103(14 \%)$. Additional procedural details are available in $>$ Table 1.

\section{Adverse events}

From a total of 3552 procedures, patients had unplanned presentations to the emergency department or were admitted to hospital within 30 days of EUS after 504 (14\%) of the procedures. Adverse events that were definitely or possibly related to EUS occurred after 69 procedures (2\%), while 435 presentations were considered unrelated. There were 64 adverse events related to upper EUS (2\% of all upper EUS procedures), 41 of which occurred following upper EUS-FNA (6\% of all upper EUSFNA). Five adverse events occurred following a lower EUS procedure (1\%), two of which involved EUS-FNA ( $9 \%$ of the 23 lower EUS procedures that involved FNA). With respect to EUS-only procedures (without FNA), there were 23 adverse events (1\%) among 2324 upper EUS procedures, and 3 events (0.6\%) among 495 lower EUS procedures.

Among the 69 definitely or possibly related adverse events, 36 (52\%) were emergency department visits alone, 5 (7\%) were direct inpatient admissions without an emergency department visit, and 28 (41\%) were emergency department visits that led to an inpatient admission. The adverse event was gastrointestinal in nature for 61 procedures $(88 \%)$ and cardiopulmonary for 8 procedures $(12 \%)$ ( $\downarrow$ Table 2$)$.

For the 33 adverse events (48\% of all definite or possible events) that resulted in an inpatient admission, the median length of stay was 9 days ( $\triangleright$ Table 3 ). No adverse event resulted in admission to an intensive care unit or patient death within 30 days of the EUS. Five adverse events (7\% of all definitely or possibly related events) required use of antibiotics, one $(1 \%)$ required endoscopic therapy, one $(1 \%)$ required surgery, and one $(1 \%)$ required blood transfusion.

\section{Risk factors for adverse events}

For EUS alone, there were no significant differences with respect to incidence of definitely or possibly related adverse events for upper vs. lower EUS $(P=0.61)$, EUS indication $(P=$ $0.63)$, type of echoendoscope $(P=0.72)$, and type of sedation $(P=0.47)$. Fewer adverse events occurred when a fellow was present $(n=9,0.5 \%)$ vs. not present $(n=17,1.6 \%)(P=0.004)$. For EUS with FNA, there were no significant differences in adverse event risk for upper vs. lower EUS $(P=0.64)$, type of sedation $(P=0.39)$, or the presence of a fellow $(P=0.52)(\triangleright$ Table 4$)$.

In the univariable logistic regression of a priori selected risk factors for adverse event risk, there was no association between adverse event risk and patient age $(O R=1.00,95 \% \mathrm{Cl} 0.61-$ $1.64 ; P=0.98)$, male sex $(\mathrm{OR}=1.34,95 \% \mathrm{Cl} 0.83-2.15 ; P=$ 0.23 ), the performance of multiple EUS procedures $(O R=1.22$, $95 \% \mathrm{Cl} 0.74-2.01 ; P=0.44)$, the performance of other procedures $(O R=0.24,95 \% \mathrm{Cl} 0.01-3.91 ; P=0.31)$, or the presence
- Table 1 Procedure characteristics

\begin{tabular}{|c|c|c|}
\hline Characteristics & $\begin{array}{l}\text { EUS only } \\
(n=2819)\end{array}$ & $\begin{array}{l}\text { EUS + FNA } \\
(n=733)\end{array}$ \\
\hline \multicolumn{3}{|l|}{ EUS approach, n (\%) } \\
\hline - Upper & $2324(82.4)$ & $710(96.9)$ \\
\hline - Lower & $495(17.6)$ & $23(3.1)$ \\
\hline \multicolumn{3}{|l|}{ EUS indication, $\mathrm{n}(\%)$} \\
\hline - $\mathrm{HPB}$ & $1286(45.6)$ & $487(66.4)$ \\
\hline - Subepithelial lesion & $1212(43.0)$ & $122(16.6)$ \\
\hline - Lymph node & $18(0.6)$ & $54(7.4)$ \\
\hline - Other & $303(10.8)$ & $70(9.6)$ \\
\hline \multicolumn{3}{|l|}{ Type of endoscope, $n(\%)$} \\
\hline - Linear & $227(8.1)$ & $733(100)$ \\
\hline - Radial & $2592(91.9)$ & $0(0.0)$ \\
\hline \multicolumn{3}{|l|}{ Sedation, n (\%) } \\
\hline - No sedation & $410(14.5)$ & $16(2.2)$ \\
\hline - Conscious sedation & $2359(83.7)$ & $703(95.9)$ \\
\hline - General anesthesia & $50(1.8)$ & $14(1.9)$ \\
\hline - Fellow present, n (\%) & $1772(62.9)$ & $439(59.9)$ \\
\hline \multicolumn{3}{|c|}{ Additional procedures performed, $\mathrm{n}(\%)$} \\
\hline - Colonoscopy & $65(2.3)$ & $2(0.3)$ \\
\hline - ERCP & $31(1.1)$ & $2(0.3)$ \\
\hline \multicolumn{3}{|l|}{ FNA details, n (\%) } \\
\hline \multicolumn{3}{|l|}{ - Needle gauge } \\
\hline . 22 or $25 G$ & NA & $514(70.1)$ \\
\hline $.19 G$ & NA & $75(10.2)$ \\
\hline - Unknown & NA & $144(19.7)$ \\
\hline \multicolumn{3}{|l|}{ Number of passes, n (\%) } \\
\hline . $1-3$ & NA & $547(74.6)$ \\
\hline.$>3$ & NA & $103(14.1)$ \\
\hline - Unknown & NA & $83(11.3)$ \\
\hline \multicolumn{3}{|c|}{$\begin{array}{l}\text { EUS, endoscopic ultrasound; FNA, fine-needle aspiration; HPB, hepatopan- } \\
\text { creaticobiliary; ERCP, endoscopic retrograde cholangiopancreatography; } \\
\text { NA, not applicable. }\end{array}$} \\
\hline
\end{tabular}

of a fellow $(\mathrm{OR}=0.69,95 \% \mathrm{Cl} 0.43-1.12 ; P=0.13)$. The use of FNA was significantly associated with a higher risk of adverse events $(\mathrm{OR}=6.64,95 \% \mathrm{Cl}$ 4.07-10.84; $P<0.001)$.

On multivariable analysis, the only factor associated with an increased risk of adverse events was the use of FNA (OR $=6.43$, $95 \% \mathrm{Cl} 3.92-10.55 ; P<0.001$ ) (> Table 5). 
- Table2 Associated risk of emergency room visit and/or hospitalization within 30 days of endoscopic ultrasound.

\begin{tabular}{|c|c|c|}
\hline Characteristics & $\begin{array}{l}\text { EUS only } \\
(n=2819)\end{array}$ & $\begin{array}{l}\text { EUS + FNA } \\
(n=733)\end{array}$ \\
\hline $\begin{array}{l}\text { Emergency department visit or } \\
\text { hospitalization, } \mathrm{n}(\%)\end{array}$ & $374(13.3)$ & $130(17.7)$ \\
\hline \multicolumn{3}{|l|}{ Relation to EUS procedure } \\
\hline - Definitely related & $7(1.9)$ & $32(24.6)$ \\
\hline - Possibly related & $19(5.1)$ & $11(8.5)$ \\
\hline - Not related & $348(93.0)$ & 87 (66.9) \\
\hline $\begin{array}{l}\text { Definitely or possibly related adverse } \\
\text { events, } n(\%)\end{array}$ & $26(0.9)$ & $43(5.9)$ \\
\hline \multicolumn{3}{|l|}{ Disposition } \\
\hline - Emergency department visit & $20(76.9)$ & $16(37.2)$ \\
\hline - Inpatient admission & $0(0.0)$ & $5(11.6)$ \\
\hline $\begin{array}{l}\text { - Emergency department visit + } \\
\text { inpatient admission }\end{array}$ & $6(23.1)$ & $22(51.2)$ \\
\hline \multicolumn{3}{|l|}{ Final diagnosis } \\
\hline - Gastrointestinal & $21(80.8)$ & $40(93.0)$ \\
\hline - Perforation & $0(0.0)$ & $2(4.7)$ \\
\hline - Pancreatitis & $1(3.9)$ & $4(9.3)$ \\
\hline - Abdominal pain & $11(42.3)$ & $26(60.5)$ \\
\hline - Other GI & $9(34.6)$ & $8(18.6)$ \\
\hline - Cardiopulmonary & $5(19.2)$ & $3(7.0)$ \\
\hline
\end{tabular}

EUS, endoscopic ultrasound; FNA, fine-needle aspiration; GI, gastrointestinal.

\section{Discussion}

In this population-based retrospective cohort study we found that unplanned emergency department visits and hospitalizations within 30 days that were definitely or possibly related to EUS without FNA occurred in $1 \%$ and $0.6 \%$ of upper and lower procedures, respectively. However, for EUS procedures that involved FNA, the risk of adverse events increased to $6 \%$ and $9 \%$, respectively. Performing FNA during EUS increased the odds of an adverse event by over sixfold in multivariable analysis.

Upper EUS with FNA is generally considered a safe procedure, during which serious adverse events are rare [14, 21, 22]. A systematic review of EUS-FNA complications, which included 10941 patients, reported a $1 \%$ risk of morbidity secondary to pancreatitis, abdominal pain, bleeding, or infection in the immediate post-procedure period [1]; however, the majority of studies in the review involved short-term follow-up, with only two articles $[9,10]$ reporting 30 -day events. Our higher reported risk of adverse events is likely due to a more inclusive definition of adverse event and longer follow-up period. Fortunately, the incidence of serious adverse events in our cohort was still low, with no event requiring intensive care or resulting in patient death.
- Table 3 Definite or possibly related adverse events leading to inpatient admissions.

\begin{tabular}{|c|c|}
\hline Characteristic & $\begin{array}{l}\text { Number of patients } \\
n=33\end{array}$ \\
\hline \multicolumn{2}{|l|}{ Indication } \\
\hline - HPB & 24 \\
\hline - Subepithelial lesion & 4 \\
\hline - Lymph node & 2 \\
\hline - Other & 3 \\
\hline \multicolumn{2}{|l|}{ Age in years } \\
\hline . $<40$ & 3 \\
\hline . 40-59 & 16 \\
\hline . 60-79 & 9 \\
\hline . $\geq 80$ & 5 \\
\hline \multicolumn{2}{|l|}{ Length of stay in days } \\
\hline . $0-5$ & 11 \\
\hline . 6-10 & 12 \\
\hline . $11-20$ & 4 \\
\hline . 21-30 & 0 \\
\hline . $31-50$ & 3 \\
\hline - $\geq 80$ & 3 \\
\hline \multicolumn{2}{|l|}{ Final diagnosis } \\
\hline - Abdominal pain & 16 \\
\hline - Pancreatitis & 2 \\
\hline - Perforation & 2 \\
\hline - Other gastrointestinal & 9 \\
\hline - Cardiopulmonary & 4 \\
\hline HPB, hepatopancreaticobiliar & \\
\hline
\end{tabular}

Very few studies have examined adverse events related to lower EUS procedures [23]. Studies on diagnostic yield of EUSFNA for rectal and pelvic lesions have reported a low incidence of adverse events but are limited by small sample sizes and reported only immediate adverse events [24,25]. One large prospective study found a strikingly high risk of adverse events related to lower EUS FNA. Levy et al. found that $21 \%$ of 502 participants followed for 2-4 months post-procedure experienced an adverse event [11]. The investigators phoned participants 7-14 days after the procedure and also saw them in clinic 2-4 months later. We found a lower rate of adverse events in our study, with only 2 of the 23 participants (9\%) who underwent lower EUS-FNA experiencing an adverse event that was definitely or possibly related to their procedure. This difference is likely due to how events were defined and captured in each study. In the study by Levy et al. adverse events included presentations that did not require medical intervention or hospi- 
- Table 4 Characteristics of adverse events within 30 days of endoscopic ultrasound procedures, with and without fine-needle aspiration.

\begin{tabular}{|c|c|c|c|c|c|c|}
\hline \multirow[t]{2}{*}{ Characteristics } & \multicolumn{3}{|l|}{ EUS only } & \multicolumn{3}{|l|}{ EUS + FNA } \\
\hline & $\begin{array}{l}\text { Definitely or possibly } \\
\text { related } \\
(n=26)\end{array}$ & $\begin{array}{l}\text { None or not } \\
\text { related } \\
(n=2793)\end{array}$ & $P$ value* & $\begin{array}{l}\text { Definitely or possibly } \\
\text { related } \\
(n=43)\end{array}$ & $\begin{array}{l}\text { None or not } \\
\text { related } \\
(n=690)\end{array}$ & $P$ value* \\
\hline \multicolumn{7}{|l|}{ EUS approach, n (\%) } \\
\hline - Upper & $23(1.0)$ & $2301(99.0)$ & \multirow[t]{2}{*}{0.61} & $41(5.8)$ & $669(94.2)$ & \multirow[t]{2}{*}{0.64} \\
\hline - Lower & $3(0.6)$ & $492(99.4)$ & & $2(8.7)$ & $21(91.3)$ & \\
\hline \multicolumn{7}{|l|}{ EUS indication, $\mathrm{n}(\%)$} \\
\hline - HPB & $10(0.8)$ & $1276(99.2)$ & & $35(7.2)$ & $452(92.8)$ & \\
\hline - Subepithelial lesion & $12(1.0)$ & $1200(99.0)$ & & $1(0.8)$ & $121(99.2)$ & \\
\hline - Lymph node & $0(0.0)$ & $18(100)$ & 0.63 & $2(3.7)$ & $52(96.3)$ & 0.022 \\
\hline - HPB & $10(0.8)$ & $1276(99.2)$ & & $35(7.2)$ & $452(92.8)$ & \\
\hline \multicolumn{7}{|l|}{ Type of endoscope, n (\%) } \\
\hline - Linear & $1(0.4)$ & $226(99.6)$ & \multirow[t]{2}{*}{0.72} & $43(5.9)$ & $690(94.1)$ & \multirow[t]{2}{*}{ NA } \\
\hline - Radial & $25(1.0)$ & $2567(99.0)$ & & NA & NA & \\
\hline \multicolumn{7}{|l|}{ Sedation, n (\%) } \\
\hline - General anesthesia & $1(2.0)$ & $49(98.0)$ & & $0(0.0)$ & $14(100)$ & \multirow[t]{3}{*}{0.39} \\
\hline - Conscious sedation & $21(0.9)$ & $2338(99.1)$ & 0.47 & $41(5.8)$ & $662(94.2)$ & \\
\hline - No sedation & $4(1.0)$ & $406(99.0)$ & & $2(12.5)$ & $14(87.5)$ & \\
\hline \multicolumn{7}{|l|}{ Fellow present, $\mathrm{n}(\%)$} \\
\hline - Yes & $9(0.5)$ & $1763(99.5)$ & \multirow[t]{2}{*}{0.004} & $28(6.4)$ & $411(93.6)$ & \multirow[t]{2}{*}{0.52} \\
\hline - No & $17(1.6)$ & $1030(98.4)$ & & $15(5.1)$ & $279(94.9)$ & \\
\hline \multicolumn{7}{|c|}{ Additional procedures performed, $\mathrm{n}(\%)$} \\
\hline - Yes & $0(0.0)$ & $96(100)$ & \multirow[t]{2}{*}{$>0.99$} & $0(0.0)$ & $4(100)$ & \multirow[t]{2}{*}{$>0.99$} \\
\hline - No & $26(1.0)$ & $2697(99.0)$ & & $43(5.9)$ & $686(94.1)$ & \\
\hline
\end{tabular}

talization, such as post-procedure asymptomatic hypotension and minor rectal bleeding [11]. The rate of serious adverse events requiring immediate intervention or hospitalization was $6 \%$, which is more comparable to our findings. Additionally, $37 \%$ and $17 \%$ of participants underwent colonoscopy and polypectomy during the same session as their lower EUS procedure, making it challenging to differentiate the risk of EUS-FNA alone from the cumulative risk of undergoing multiple procedures on the same day [11]. Our study is the first to examine the risk of lower EUS with and without FNA in isolation of other lower endoscopic procedures.

Our findings may help to inform health care providers and patients contemplating undergoing EUS. We have demonstrated that upper and lower EUS without FNA for evaluation, surveillance, and staging is very safe. These observations do not support individualized counseling based on EUS indication, the type of echoendoscope used, and patient sex or age, as these factors were not found to be related to adverse event risk. The presence of a fellow did not increase adverse event risk in the univariable or multivariable analyses, an important finding for advanced endoscopy educators who work with trainees. A previous study found that adverse event risk was higher for EUS procedures performed with a trainee present, but this was limited to the first 3 months of training [13]. In our study, fewer adverse events occurred when a fellow was present for EUS only procedures, with a low overall risk (<1\%). There was no difference in adverse event risk for EUS-FNA procedures performed with or without a fellow present.

This study has several strengths. First, it is population based and therefore less prone to referral bias as seen in smaller single-center studies. Second, we utilized a robust process to identify potential adverse events based on previously reported methodology [13-15]. The medical record of every possible adverse event was formally reviewed rather than relying on administrative or survey data to assess outcomes. Finally, relatively few participants underwent ERCP, colonoscopy, or poly- 
- Table 5 Factors associated with adverse events within 30 days of endoscopic ultrasound procedures.

\begin{tabular}{|c|c|c|c|c|}
\hline \multirow[t]{2}{*}{ Characteristics } & \multicolumn{2}{|l|}{ Univariable } & \multicolumn{2}{|l|}{ Multivariable } \\
\hline & Adverse event $\mathrm{OR}(95 \% \mathrm{Cl})$ & $P$ value & Adverse event OR $(95 \% \mathrm{Cl})$ & $P$ value \\
\hline \multicolumn{5}{|l|}{ Patient characteristics } \\
\hline - Age $\geq 65$ & $1.00(0.61-1.64)$ & 0.98 & $0.80(0.48-1.32)$ & 0.38 \\
\hline - Male sex & $1.34(0.83-2.15)$ & 0.23 & $1.28(0.79-2.07)$ & 0.31 \\
\hline - Multiple EUS procedures ${ }^{1}$ & $1.22(0.74-2.01)$ & 0.44 & $1.10(0.67-1.82)$ & 0.71 \\
\hline - Additional procedures ${ }^{2}$ & $0.24(0.01-3.91)$ & 0.31 & $0.40(0.02-6.57)$ & 0.52 \\
\hline \multicolumn{5}{|l|}{ Procedural characteristics } \\
\hline - Fellow present & $0.69(0.43-1.12)$ & 0.13 & $0.73(0.45-1.18)$ & 0.20 \\
\hline - Addition of FNA & $6.64(4.07-10.84)$ & $<0.001$ & $6.43(3.92-10.55)$ & $<0.001$ \\
\hline
\end{tabular}

pectomy concurrently with EUS. This allowed us to evaluate the specific risk of adverse events associated with EUS, rather than the cumulative risk for participants undergoing multiple procedures on the same day.

Our study also has several limitations. We were unable to capture individuals who may have experienced an adverse event but visited their primary physician rather than going to an acute care facility. While such encounters would reflect less serious events, the excess health care utilization resulting from any unplanned health care presentation is worthy of consideration. Moreover, symptoms such as post-procedure rectal bleeding can adversely affect patients even if they are never brought to medical attention. Our lower EUS data only apply to distal lesions as we did not have any patients who underwent EUS of the proximal colon. This is consistent with other studies in this field. The median length of stay of patients admitted for an adverse event was 9 days. Although a third were discharged in 5 days or less, among those admitted for longer it is likely that the underlining diseases of some patients (e.g. cancer) contributed to prolongation of hospitalization. We could not determine the proportion of a hospitalization stay directly related to the adverse event. In addition, owing to the low number of endoscopists performing EUS procedures at our institution, we could not report their individual outcomes. We also could not determine whether a trainee participated as an observer or an operator during procedures. Finally, our study may have misclassification bias and limited generalizability, as it was retrospective and conducted at a single center.

In conclusion, upper and lower EUS were shown to be safe procedures with adverse events leading to unplanned emergency department visits and hospitalization following $2 \%$ of procedures. The addition of FNA increased the risk of adverse events sixfold and events requiring inpatient admission were rare. The rate of adverse events related to lower EUS procedures was low when they were considered in isolation of other lower endoscopic procedures.

\section{Acknowledgment}

Paul D. James was supported by a Canadian Institutes of Health Research award and an Alberta Innovates Clinical Fellowship award.

\section{Competing interests}

Dr. Forbes is a consultant for Boston Scientific, is on the speakers' bureau for Pentax Medical and has received unrelated research funding from Pentax Medical. Dr. Kaplan is a speaker and/or consultant for AbbVie, Janssen, Pfizer, Gilead and Takeda and has received unrelated research funding from Ferring, Janssen, AbbVie, GlaxoSmithKline, Merck and Shire. Dr. Heitman is a consultant for Pendopharm.

\section{References}

[1] Wang K-X, Ben Q-W, Jin Z-D et al. Assessment of morbidity and mortality associated with EUS-guided FNA: a systematic review. Gastrointest Endosc 2011; 73: 283-290

[2] Early DS, Acosta RD, Chandrasekhara V et al. Adverse events associated with EUS and EUS with FNA. Gastrointest Endosc 2013; 77 : 839-843

[3] Eloubeidi M, Tamhane A, Lopes T et al. Cervical esophageal perforations at the time of endoscopic ultrasound: a prospective evaluation of frequency, outcomes, and patient management. Gastrointest Endosc 2009; 69: \$240

[4] Varadarajulu S, Eloubeidi MA. Frequency and significance of acute intracystic hemorrhage during EUS-FNA of cystic lesions of the pancreas. Gastrointest Endosc 2004; 60: 631-635

[5] O’Toole D, Palazzo L, Arotçarena R et al. Assessment of complications of EUS-guided fine-needle aspiration. Gastrointest Endosc 2001; 53 : 470-474

[6] Eloubeidi MA, Gress FG, Savides T] et al. Acute pancreatitis after EUSguided FNA of solid pancreatic masses: a pooled analysis from EUS centers in the United States. Gastrointest Endosc 2004; 60: 385-389 
[7] Cotton PB, Eisen G, Romagnuolo J et al. Grading the complexity of endoscopic procedures: results of an ASGE working party. Gastrointest Endosc 2011; 73: 868-874

[8] Zhu H, Jiang F, Zhu J et al. Assessment of morbidity and mortality associated with endoscopic ultrasound-guided fine-needle aspiration for pancreatic cystic lesions: a systematic review and meta-analysis. Dig Endosc 2017; 29: 667-675

[9] Eloubeidi MA, Tamhane A. EUS-guided FNA of solid pancreatic masses: a learning curve with 300 consecutive procedures. Gastrointest Endosc 2005; 61: 700-708

[10] Eloubeidi MA, Chen VK, Eltoum IA et al. Endoscopic ultrasound-guided fine needle aspiration biopsy of patients with suspected pancreatic cancer: diagnostic accuracy and acute and 30-day complications. Am J Gastroenterol 2003; 98: 2663-2668

[11] Levy M], Abu Dayyeh BK, Fujii LL et al. Prospective evaluation of adverse events following lower gastrointestinal tract EUS FNA. Am J Gastroenterol 2014; 109: 676-685

[12] Brown L, Clark N, Conway J et al. Rectal ultrasound with fine needle aspiration: an underutilized modality for delineating and diagnosing perirectal, presacral, and pelvic lesions. Endosc Int Open 2019; 7: E171-E177

[13] Khan U, Abunassar M, Chatterjee A et al. Advanced endoscopy trainee involvement early in EUS training may be associated with an increased risk of adverse events. J Can Assoc Gastroenterol 2020; 3: 83-90

[14] Cotton PB, Eisen GM, Aabakken L et al. A lexicon for endoscopic adverse events: report of an ASGE workshop. Gastrointest Endosc 2010; 71: $446-454$

[15] Hilsden RJ, Dube C, Heitman S] et al. The association of colonoscopy quality indicators with the detection of screen-relevant lesions, adverse events, and postcolonoscopy cancers in an asymptomatic Canadian colorectal cancer screening population. Gastrointest Endosc 2015; 82: 887-894
[16] Causada-Calo N, Bishay K, Albashir S et al. Association between age and complications after outpatient colonoscopy. JAMA Netw Open 2020; 3: e208958-e208958

[17] Warren JL, Klabunde CN, Mariotto AB et al. Adverse events after outpatient colonoscopy in the Medicare population. Ann Intern Med 2009; 150: 849-857

[18] Day LW, Kwon A, Inadomi JM et al. Adverse events in older patients undergoing colonoscopy: a systematic review and meta-analysis. Gastrointest Endosc 2011; 74: 885-896

[19] Dumonceau J-M, Kapral C, Aabakken L et al. ERCP-related adverse events: European Society of Gastrointestinal Endoscopy (ESGE) Guideline. Endoscopy 2020; 52: 127-149

[20] Katanuma A, Maguchi H, Yane K et al. Factors predictive of adverse events associated with endoscopic ultrasound-guided fine needle aspiration of pancreatic solid lesions. Dig Dis Sci 2013; 58: 2093-2099

[21] Jenssen C, Hocke M, Fusaroli P et al. EFSUMB Guidelines on Interventional Ultrasound (INVUS), Part IV - EUS-guided interventions: general aspects and EUS-guided sampling (long version). Eur J Ultrasound 2016; 37: E33-E76

[22] Polkowski M, Jenssen C, Kaye P et al. Technical aspects of endoscopic ultrasound (EUS)-guided sampling in gastroenterology: European Society of Gastrointestinal Endoscopy (ESGE) Technical Guideline March 2017. Endoscopy 2017; 49: 989-1006

[23] Alvarez-Sánchez MV, Jenssen C, Faiss S et al. Interventional endoscopic ultrasonography: an overview of safety and complications. Surg Endosc 2014; 28: 712-734

[24] Sasaki Y, Niwa Y, Hirooka Y et al. The use of endoscopic ultrasoundguided fine-needle aspiration for investigation of submucosal and extrinsic masses of the colon and rectum. Endoscopy 2005; 37: 154160

[25] Hassan GM, Paquin SC, Albadine R et al. Endoscopic ultrasound-guided FNA of pelvic lesions: a large single-center experience: EUS-FNA of pelvic lesions. Cancer Cytopathol 2016; 124: 836-841 